\title{
Comparative Study of Infliximab Versus Adalimumab in Refractory Uveitis due to Behçet's Disease: National Multicenter Study of 177 Cases
}

Belén Atienza-Mateo, ${ }^{1}$ José Luis Martín-Varillas, ${ }^{1}$ Vanesa Calvo-Río, ${ }^{1}$ Rosalía Demetrio-Pablo, ${ }^{1}$ Emma Beltrán, ${ }^{2}$ Juan Sánchez-Bursón, ${ }^{3}$ Marina Mesquida, ${ }^{4}$ Alfredo Adan, ${ }^{4}$ María Victoria Hernández, ${ }^{4}$ Marisa Hernández-Garfella, ${ }^{5}$ Elia Valls-Pascual, ${ }^{6}$ Lucía Martínez-Costa, ${ }^{6}$ Agustí Sellas-Fernández, ${ }^{7}$ Miguel Cordero-Coma, ${ }_{1}^{8}$ Manuel Díaz-Llopis, ${ }^{9}$ Roberto Gallego, ${ }^{9}$ José L. García-Serrano, ${ }^{10}$ Norberto Ortego-Centeno, ${ }^{10}$ José M. Herreras, ${ }^{11}$ Alejandro Fonollosa, ${ }^{12}$ Ángel M. Garcia-Aparicio, ${ }^{13}$ Olga Maíz-Alonso, ${ }^{14}$ Ana Blanco,${ }^{14}$ Ignacio Torre-Salaberri, ${ }^{15}$ Cruz Fernandez-Espartero, ${ }^{16}$ Vega Jovaní, ${ }^{17}$ Diana Peiteado, ${ }^{18}$ Esperanza Pato, ${ }^{19}$ Juan Cruz, ${ }^{20}$ Carlos Férnandez-Cid, ${ }^{20}$ Elena Aurrecoechea, ${ }^{21}$ Miriam García-Arias, ${ }^{22}$ Santos Castañeda, ${ }^{22}$ Miguel A. Caracuel-Ruiz, ${ }^{23}$ Carlos A. Montilla-Morales, ${ }^{24}$ (D) Antonio Atanes-Sandoval, ${ }^{25}$ Félix Francisco, ${ }^{26}$ Santos Insua, ${ }^{27}$ Senen González-Suárez, ${ }^{28}$ Amalia Sanchez-Andrade, ${ }^{29}$ Fernando Gamero, ${ }^{30}$ Luis F. Linares Ferrando, ${ }^{31}$ F. Romero-Bueno, ${ }^{32}$ A. Javier García-González, Raquel Almodóvar González, ${ }^{34}$ Enrique Minguez Muro, ${ }^{35}$ Carmen Carrasco-Cubero, ${ }^{36}$ Alejandro Olive, ${ }^{37}$ Águeda Prior, ${ }^{37}$ Julio Vázquez, ${ }^{38}$ Oscar Ruiz-Moreno, ${ }^{39}$ Fernando Jiménez-Zorzo, ${ }^{39}$ Javier Manero, ${ }^{39}$ Santiago Muñoz Fernandez ${ }^{40}$ Cristina Fernández-Carballido, ${ }^{41}$ (D) Esteban Rubio-Romero, ${ }^{42}$ Fred Antón Pages, ${ }^{43}$ Francisco J. Toyos-Sáenz de Miera, ${ }^{44}$ Myriam Gandia Martinez, ${ }^{45}$ David Díaz-Valle, ${ }^{19}$ Francisco J. López Longo, ${ }^{16}$ Joan M. Nolla, ${ }^{46}$ Enrique Raya Álvarez, ${ }^{10}$ Marcelino Revenga Martínez, ${ }^{47}$ Julio José González-López, ${ }^{47}$ Paz Rodríguez-Cundin, ${ }^{1}$ José L. Hernández, ${ }^{1}$ Miguel A. González-Gay, ${ }^{1}$ (D) and Ricardo Blanco ${ }^{1}$ (D)

Objective. To compare the efficacy of infliximab (IFX) versus adalimumab (ADA) as a first-line biologic drug over 1 year of treatment in a large series of patients with refractory uveitis due to Behçet's disease (BD).

Methods. We conducted an open-label multicenter study of IFX versus ADA for BD-related uveitis refractory to conventional nonbiologic treatment. IFX or ADA was chosen as the first-line biologic agent based on physician and patient agreement. Patients received 3-5 mg/kg intravenous IFX at 0, 2, and 6 weeks and every 4-8 weeks thereafter, or $40 \mathrm{mg}$ subcutaneous ADA every other week without a loading dose. Ocular parameters were compared between the 2 groups.

Results. The study included 177 patients (316 affected eyes), of whom 103 received IFX and 74 received ADA. There were no significant baseline differences between treatment groups in main demographic features, previous therapy, or ocular sign severity. After 1 year of therapy, we observed an improvement in all ocular parameters in both groups. However, patients receiving ADA had significantly better outcomes in some parameters, including improvement in anterior chamber inflammation $(92.31 \%$ versus $78.18 \%$ for IFX; $P=0.06)$, improvement in vitritis $(93.33 \%$ versus $78.95 \%$ for IFX; $P=0.04$ ), and best-corrected visual acuity (mean \pm SD $0.81 \pm 0.26$ versus $0.67 \pm 0.34$ for IFX; $P=0.001$ ). A nonsignificant difference was seen for macular thickness (mean \pm SD $250.62 \pm 36.85$ for ADA versus $264.89 \pm 59.74$ for IFX; $P=0.15)$, and improvement in retinal vasculitis was similar between the 2 groups $(95 \%$ for ADA versus $97 \%$ for IFX; $P=0.28)$. The drug retention rate was higher in the ADA group $(95.24 \%$ versus $84.95 \%$ for IFX; $P=0.042)$.

Conclusion. Although both IFX and ADA are efficacious in refractory BD-related uveitis, ADA appears to be associated with better outcomes than IFX after 1 year of follow-up.

Belén Atienza-Mateo, MD, José Luis Martín-Varillas, MD, Vanesa CalvoRío, MD, PhD, Rosalía Demetrio-Pablo, MD, PhD, Paz Rodríguez-Cundin, MD, PhD, José L. Hernández, MD, PhD, Miguel A. González-Gay, MD, PhD, Ricardo Blanco, MD, PhD: Hospital Universitario Marqués de Valdecilla Santander, Spain; ${ }^{2} E m m a$ Beltrán, MD: Hospital del Mar, Barcelona, Spain; ${ }^{3} J u a n$ Sánchez-Bursón, MD, PhD: Hospital de Valme, Sevilla, Spain; ${ }^{4}$ Marina
Mesquida, MD, PhD, Alfredo Adan, MD, PhD, María Victoria Hernández, MD: Hospital Clinic, Barcelona, Spain; ${ }^{5}$ Marisa Hernández-Garfella, MD: Hospital General Universitario de Valencia, Valencia, Spain; ${ }^{6}$ Elia Valls-Pascual, MD, Lucía Martínez-Costa, MD, PhD: Hospital Peset, Valencia, Spain; ${ }^{7}$ Agustí SellasFernández, MD: Hospital Vall d'Hebron, Barcelona, Spain; ${ }^{8}$ Miguel CorderoComa, MD, PhD: Hospital de León, León, Spain; ${ }^{9}$ Manuel Díaz-Llopis, MD, PhD, 


\section{INTRODUCTION}

Behçet's disease (BD) is a systemic vasculitis characterized by recurrent oral and/or genital ulcers, skin lesions, and ocular involvement, although it can affect multiple organs $(1,2)$. One of the major causes of disability in BD is uveitis. Several studies have indicated that the risk of severe visual loss ranges from $13-74 \%$ within 6-10 years after the onset of uveitis (3-6).

The prognosis of ocular involvement has improved over recent decades due to the use of conventional and biologic immunosuppressive therapies (7). According to the 2014 expert panel recommendations for the use of anti-tumor necrosis factor (anti-TNF) drugs in patients with ocular inflammatory disorders, infliximab (IFX; good-quality evidence) or adalimumab (ADA; moderatequality evidence) may be considered as the first- or second-line glucocorticoid-sparing therapy for patients with ophthalmic manifestations of $\mathrm{BD}$, and IFX may be considered as the first- or secondline treatment for acute exacerbations of preexisting $\mathrm{BD}$ (8).

In 2016, ADA was reported to be the only biologic drug that demonstrated efficacy in randomized double-blind, phase III studies of noninfectious intermediate posterior uveitis and panuveitis (the Efficacy and Safety of Adalimumab in Patients With Active Non-infectious Uveitis [VISUAL I] trial and the Efficacy and Safety of Adalimumab in Subjects With Inactive Non-infectious Uveitis [VISUAL II] trial) $(9,10)$. Consequently, ADA was approved by the European Medicines Agency (EMA) and the US Food and Drug Administration (FDA) for noninfectious non-anterior uveitis. How-

Roberto Gallego, MD, PhD: Hospital Universitario La Fe, Valencia, Spain; ${ }^{10}$ José L. García-Serrano, MD, PhD, Norberto Ortego-Centeno, MD, PhD, Enrique Raya Álvarez, MD, PhD: Hospital Universitario San Cecilio, Granada, Spain; ${ }^{11}$ José M. Herreras, MD, PhD: Hospital Universitario IOBA, Valladolid, Spain; ${ }^{12}$ Alejandro Fonollosa, MD, PhD: Hospital de Cruces, Bilbao, Spain; ${ }^{13}$ Ángel M. Garcia-Aparicio, MD: Hospital de Toledo, Toledo, Spain; ${ }^{14}$ Olga Maíz-Alonso, MD, Ana Blanco, MD: Hospital Universitario de Donostia, San Sebastián, Spain; ${ }^{15}$ Ignacio Torre-Salaberri, MD: Hospital Universitario de Basurto, Bilbao, Spain; ${ }^{16}$ Cruz Fernandez-Espartero, MD, Francisco J. López Longo, MD, PhD: Hospital Universitario de Móstoles, Madrid, Spain; ${ }^{17}$ Vega Jovaní, MD, PhD: Hospital General de Alicante, Alicante, Spain; ${ }^{18}$ Diana Peiteado, MD, PhD: Hospital La Paz, Madrid, Spain; ${ }^{19}$ Esperanza Pato, MD, David Díaz-Valle, MD, PhD: Hospital Clínico San Carlos, Madrid, Spain; ${ }^{20}$ Juan Cruz, MD, Carlos Férnandez-Cid, MD: Hospital de Pontevedra, Pontevedra, Spain; ${ }^{21}$ Elena Aurrecoechea, MD, PhD: Hospital Sierrallana, Torrelavega, Spain; ${ }^{22}$ Miriam García-Arias, MD, Santos Castañeda, MD, PhD: Hospital Universitario de la Princesa, IIS-Princesa, Madrid, Spain; ${ }^{23}$ Miguel A. Caracuel-Ruiz, MD, PhD: Hospital Universitario Reina Sofía, Córdoba, Spain; ${ }^{24}$ Carlos A. Montilla-Morales, MD, PhD: Hospital Clínico Universitario de Salamanca, Salamanca, Spain; ${ }^{25}$ Antonio Atanes-Sandoval, MD, PhD: Complejo Hospitalario Universitario A Coruña, A Coruña, Spain ${ }^{26}$ Félix Francisco, MD: Hospital Doctor Negrín, Las Palmas de Gran Canaria, Spain; ${ }^{27}$ Santos Insua, MD: Hospital Universitario Santiago de Compostela, A Coruña, Spain; ${ }^{28}$ Senen González-Suárez, MD: Hospital de Cabueñes, Gijón, Spain; ${ }^{29}$ Amalia Sanchez-Andrade, MD, PhD: Hospital Lucus Augusti, Lugo, Spain; ${ }^{30}$ Fernando Gamero, MD: Hospital San Pedro Alcántara, Cáceres, Spain; ${ }^{31}$ Luis F. Linares Ferrando, MD, PhD: Hospital Virgen de la Arrixaca, Murcia, Spain; ${ }^{32} \mathrm{~F}$. Romero-Bueno, MD, PhD: Jiménez Díaz Foundation University Hospital, Madrid, Spain; ${ }^{33}$ A. Javier García-González, MD: Instituto de Investigación Hospital 12 de Octubre, Madrid, Spain; ${ }^{34}$ Raquel Almodóvar González, MD: Hospital Universitario Fundación de Alcorcón, Madrid, Spain; ${ }^{35}$ Enrique Minguez Muro, MD, PhD: Hospital Clínico de Zaragoza, Zaragoza, Spain; ${ }^{36}$ Carmen Carrasco-Cubero, MD: Hospital de Mérida, Mérida, Spain; ${ }^{37}$ Alejandro Olive, MD, PhD, Águeda Prior, MD: Germans Trias i Pujol Hospital, Barcelona, Spain; ${ }^{38}$ Julio Vázquez, MD: Hospital de Ferrol, A Coruña, Spain; ever, underlying diseases included in the VISUAL trials were very heterogeneous. Furthermore, the VISUAL trials included very few cases of BD-related uveitis treated with ADA (12 patients [11\%] in VISUAL I and 10 patients [9\%] in VISUAL II). Therefore, conclusions regarding the efficacy of ADA in BD were limited. Moreover, little is known of differences in outcome for patients with BD-related uveitis treated with IFX versus those treated with ADA. Only one previous study has compared the efficacy of these 2 anti-TNF agents in adult patients with refractory noninfectious uveitis (11). However, that study included a very heterogeneous group of patients, including those with diseases unrelated to $\mathrm{BD}$, such as juvenile idiopathic arthritis, spondyloarthritis, and sarcoidosis. Moreover, patients with refractory uveitis due to $\mathrm{BD}$ represented only $36 \%$ of the cases. Therefore, there was no specific comparison between IFX and ADA for refractory BD-related uveitis.

Taking into account all of these considerations, we aimed to compare the efficacy and safety of IFX versus ADA as the first-line biologic drug in a large series of patients with refractory uveitis exclusively due to BD who were followed up for 1 year.

\section{PATIENTS AND METHODS}

\section{Study design, enrollment criteria, and definitions.}

We conducted an observational, open-label multicenter study including 177 patients with refractory uveitis due to BD who were treated with IFX or ADA as first-line biologic therapy. The dosing schedule was as follows: for IFX, 3-5 mg/kg intravenously (IV) at

${ }^{39}$ Oscar Ruiz-Moreno, MD, PhD, Fernando Jiménez-Zorzo, MD, Javier Manero, MD: Hospital Universitario Miguel Servet, Zaragoza, Spain; ${ }^{40}$ Santiago Muñoz Fernandez, MD, PhD: Hospital Universitario Infanta Sofía, Madrid, Spain; ${ }^{41}$ Cristina Fernández-Carballido, MD, PhD: Hospital General Universitario de Elda, Alicante, Spain; ${ }^{42}$ Esteban Rubio-Romero, MD: Hospital Universitario Virgen del Rocío, Sevilla, Spain; ${ }^{43}$ Fred Antón Pages, MD: Complejo Asistencial de Palencia, Palencia, Spain; ${ }^{44}$ Francisco J. Toyos-Sáenz de Miera, MD, PhD: Hospital Virgen de la Macarena, Sevilla, Spain; ${ }^{45}$ Myriam Gandia Martinez, MD, PhD: Hospital Puerta del Mar, Cádiz, Spain; ${ }^{46}$ Joan M. Nolla, MD, PhD: Hospital Universitari de Bellvitge, Barcelona, Spain; ${ }^{47}$ Marcelino Revenga Martínez, MD, PhD, Julio José González-López, MD, PhD: Hospital Universitario Ramón y Cajal, Madrid, Spain.

Drs. Atienza-Mateo, Martín-Varillas, and Calvo-Río contributed equally to this work.

Dr. Atienza-Mateo has received research support from Roche, Celgene, and GlaxoSmithKline. Dr. Martín-Varillas has received research support from AbbVie, Pfizer, and Celgene. Dr. Calvo-Río has received consulting fees and speaking fees from Abbott, Eli Lilly, Celgene, Grünenthal, and UCB Pharma (less than $\$ 10,000$ each) and research support from MSD and Roche. Dr. Sánchez-Bursón has received speaking fees from Pfizer (less than $\$ 10,000$ ) and research support from Eli Lilly and Janssen. Dr. Adán has received consulting fees and speaking fees from AbbVie (less than $\$ 10,000$ each) and research support from AbbVie. Dr. Valls-Pascual has received consulting fees and speaking fees from AbbVie, Eli Lilly, Pfizer, MSD, Novartis, Janssen, Bristol-Myers Squibb, and UCB Pharma (less than $\$ 10,000$ each) and research support from Roche, Novartis, and AbbVie. Dr. Sellas-Fernández has received consulting fees and speaking fees from Abbott, Eli Lilly, Celgene, Pfizer, Schering-Plough, Janssen, Novartis, and Nordic Pharma (less than $\$ 10,000$ each). Dr. Cordero-Coma has received consulting fees, speaking fees, and/or honoraria from AbbVie, MSD, Allergan, and UCB (less than $\$ 10,000$ each). Dr. Gallego has received consulting fees and speaking fees from Novartis, Roche, Bloss, Heidelberg Engineering, Indo, and Novo Nordisk (less than \$10,000 each) and research support from Boehringer Ingelheim, Novartis, Roche, and Oxurion. Dr. 
0, 2, and 6 weeks and every 4-8 weeks thereafter; and for ADA, $40 \mathrm{mg}$ subcutaneously every other week without loading dose.

All of the BD patients had uveitis refractory to glucocorticoids and had previously received at least 1 conventional synthetic immunosuppressive drug. Of the 177 patients, 103 received IFX and 74 received ADA. Partial information on 124 patients in this series was previously reported (12). Patients were followed up at 52 uveitis referral units in Spanish hospitals. Patients were diagnosed as having $\mathrm{BD}$ according to the proposed International Criteria for BD (13), and all patients fulfilled the recently proposed criteria for BD (14).

Since uveitis is an off-label indication for IFX, written informed consent was requested and obtained from all patients in the IFX group. Written informed consent was also obtained from patients in the ADA group, since ADA was prescribed before approval by the EMA and the FDA for the treatment of noninfectious and non-anterior uveitis.

Malignancy or systemic infectious diseases, including hepatitis $\mathrm{B}$ or $\mathrm{C}$ infection, were excluded before starting anti-TNF treatment, as previously described (12,15-21). To exclude latent tuberculosis (TB), patients underwent a tuberculin skin test (purified protein derivative) and/or an interferon- $\gamma$ assay (QuantiFeron) and a chest radiograph, as indicated by the Spanish National Guidelines for all patients receiving biologic drugs. If latent TB was present, prophylaxis with isoniazid was initiated at least 4 weeks before beginning biologic treatment and maintained for 9 months.

Uveitis was anatomically classified according to the Standardization of Uveitis Nomenclature (SUN) Working Group (22). Remission was defined as the absence of signs of any intraocular inflammation for at least 3 months. Intraocular inflammation was considered to be present if there was anterior or poste-

Ortego-Centeno has received research support from Abbott. Dr. Herreras has received consulting fees and speaking fees from AbbVie (less than $\$ 10,000)$. Dr. Blanco has received consulting fees and speaking fees from AbbVie (less than $\$ 10,000$ ). Dr. Jovaní has received consulting fees and speaking fees from AbbVie (less than $\$ 10,000$ ) and research support from AbbVie, MSD, Novartis, and Pfizer. Dr. Peiteado has received speaking fees from AbbVie, Roche, and MSD (less than $\$ 10,000$ each) and research support from AbbVie, Eli Lilly, MSD, and Roche. Dr. Pato has received consulting fees and speaking fees from AbbVie, MSD, Novartis, and Nordic Pharma (less than $\$ 10,000$ each). Dr. Caracuel-Ruiz has received speaking fees from Eli Lilly, Sanofi-Genzyme, and Amgen (less than $\$ 10,000$ each) and research support from those companies. Dr. Atanes-Sandoval has received consulting fees and speaking fees from Abbott, MSD, Menarini, Gebro Pharma, Grünenthal, Roche, Pfizer, Novartis, Celgene, Bristol-Myers Squibb, and Lacer (less than $\$ 10,000$ each). Dr. Francisco has received consulting fees and speaking fees from Roche, Sanofi, Eli Lilly, Abbott, and Janssen (less than $\$ 10,000$ each). Dr. Linares Ferrando has received consulting fees and speaking fees from AbbVie, MSD, Novartis, Pfizer, Grünenthal, and UCB (less than $\$ 10,000$ each) and research support from Pfizer. Dr. Almodóvar González has received consulting fees and speaking fees from AbbVie, Celgene, Gebro Pharma, Janssen, Eli Lilly, MSD, Novartis, Pfizer, and UCB (less than $\$ 10,000$ each) and research support from those companies. Dr. Carrasco Cubero has received consulting fees and speaking fees from Janssen, MSD, AbbVie, Novartis, Bristol-Myers Squibb, and Celgene (less than $\$ 10,000$ each) and research support from those companies. Dr. Olive has received consulting fees from Eli Lilly, Almirall, AbbVie, and Pfizer (less than $\$ 10,000$ each). Dr. Fernández-Carballido has received consulting fees and speaking fees from AbbVie, Celgene, Janssen, Novartis, Pfizer, MSD, Roche, and UCB Pharma (less than $\$ 10,000$ each) rior chamber inflammation, retinal vasculitis, papillitis, or cystoid macular edema (CME). A relapse was defined as a new flare of uveitis in a patient whose disease was in remission (23).

The conventional immunosuppressive drugs and dosages given most frequently before ADA or IFX treatment were cyclosporin A (CsA; 3-6 mg/kg/day orally), methotrexate (MTX; 7.5-25 mg/week subcutaneously), and azathioprine (AZA; 100-150 mg/day orally). Consistent with the VISUAL I and VISUAL II trials, the maintenance dose of ADA was $40 \mathrm{mg}$ subcutaneously every other week. However, the VISUAL I and II trials were published after the present study had begun, and therefore, patients from our series did not receive a loading dose of ADA. Patients in the IFX group received a standard loading dose of $3-5 \mathrm{mg} / \mathrm{kg} \mathrm{IV}$ at weeks 0,2 , and 6 and a maintenance dose every 4-8 weeks thereafter. The anti-TNF agents were administered in combination with conventional immunosuppressive drugs in 78 of 102 patients receiving IFX (76.5\%) and in 52 patients receiving ADA (70.3\%) and as monotherapy in the remaining cases. The conventional drugs used in combination with ADA and IFX are shown in Table 1.

Outcome variables. The outcome variables were efficacy, safety, and drug retention rate. To determine efficacy, intraocular inflammation, macular thickness, visual acuity, degree of immunosuppression load, number of relapses, and glucocorticoid-sparing effect were assessed. These outcome variables were recorded at baseline, 1 week, 2 weeks, 1 month, 3 months, 6 months, and 1 year after the start of IFX or ADA treatment. They were assessed in each center according to a follow-up protocol agreed upon beforehand.

and research support from those companies. Dr. Rubio-Romero has received consulting fees and speaking fees from Eli Lilly, Sanofi, Biogen, and Novartis (less than $\$ 10,000$ each) and has received research support from Eli Lilly, Pfizer, AbbVie, Novartis, MSD, Celltrion, Sanofi, Roche, Gebro, Nordic, Grünenthal, and UCB. Dr. López-Longo has received consulting fees and speaking fees from AbbVie, Actelion, Bristol-Myers Squibb, GlaxoSmithKline, MSD, Pfizer, Roche, and UCB Pharma (less than $\$ 10,000$ each) and research support from AbbVie and GlaxoSmithKline. Dr. Nolla has received consulting fees and speaking fees from AbbVie, Amgen, Bristol-Myers Squibb, Gebro, Kern, Eli Lilly, MSD, Novartis, Pfizer, Roche, Sanofi, and UCB (less than $\$ 10,000$ each) and research support from AbbVie, Amgen, Biogen, Bristol-Myers Squibb, Gebro, Eli Lilly, MSD, Mylan, Roche, Sandoz, Sanofi, and UCB. Dr. Álvarez has received consulting fees and speaking fees from Eli Lilly (less than \$10,000) and research support from MSD. Dr. González-López has received consulting fees and speaking fees from Gilead (less than $\$ 10,000$ each) and research support from AbbVie and Bayer. Dr. González-Gay has received consulting fees and speaking fees from Abbott, Pfizer, Roche, and MSD (less than $\$ 10,000$ each) and from Sanofi (more than \$10,000) and research support from Abbott, MSD, and Roche. Dr. Blanco has received consulting fees and speaking fees from Abbott, Pfizer, Roche, Bristol-Myers Squibb, Janssen, and MSD (less than $\$ 10,000$ each) and research support from Abbott, MSD, and Roche. No other disclosures relevant to this article were reported.

Address correspondence to Miguel A. González-Gay, MD, PhD, or Ricardo Blanco, MD, PhD, Hospital Universitario Marqués de Valdecilla, Rheumatology Division, Avenida Valdecilla s/n, 39008 Santander, Spain. E-mail: miguelaggay@hotmail.com or rblanco@humv.es.

Submitted for publication August 29, 2018; accepted in revised form June 19, 2019. 
Table 1. Baseline features of and follow-up data for a series of 177 patients receiving IFX or ADA for refractory uveitis due to Behçet's disease*

\begin{tabular}{|c|c|c|c|}
\hline & $\begin{array}{c}\text { IFX } \\
(n=103)\end{array}$ & $\begin{array}{c}\text { ADA } \\
(n=74)\end{array}$ & $P$ \\
\hline No. of patients/no. of affected eyes & $103 / 185$ & $74 / 131$ & - \\
\hline Age, mean \pm SD years & $40.4 \pm 10.1$ & $38.7 \pm 1.3$ & 0.29 \\
\hline Sex, no. of men/no. of women & $55 / 48$ & $39 / 35$ & 0.93 \\
\hline HLA-B51 positive, $\%$ & 69.4 & 68.9 & 0.74 \\
\hline $\begin{array}{l}\text { Duration of uveitis before anti-TNF therapy, } \\
\text { median (IQR) months }\end{array}$ & $36(12-72)$ & $24(12-60)$ & 0.69 \\
\hline \multicolumn{4}{|l|}{ Ocular features at start of anti-TNF therapy } \\
\hline Anterior chamber inflammation grade, median (IQR) & $1(0-2)$ & $1(0-2)$ & 0.25 \\
\hline Vitritis grade, median (IQR) & $1(0-2)$ & $1(0-2)$ & 0.12 \\
\hline$B C V A$, mean $\pm S D$ & $0.50 \pm 0.35$ & $0.56 \pm 0.34$ & 0.08 \\
\hline Macular thickness, mean \pm SD $\mu \mathrm{m}$ & $331.11 \pm 131.97$ & $346.37 \pm 136.14$ & 0.49 \\
\hline No. of patients with retinal vasculitis & 114 & 78 & 0.51 \\
\hline No. of patients with choroiditis & 41 & 10 & $<0.01$ \\
\hline \multicolumn{4}{|l|}{ Uveitis pattern, no. (\%) } \\
\hline Bilateral & $82(79.61)$ & $57(77.03)$ & 0.68 \\
\hline Unilateral & $21(20.39)$ & $17(22.97)$ & 0.68 \\
\hline Anterior & $11(10.68)$ & $14(18.92)$ & 0.19 \\
\hline Posterior & $28(27.18)$ & $14(18.92)$ & 0.19 \\
\hline Panuveitis & $64(62.14)$ & $45(60.81)$ & 0.19 \\
\hline Intermediate & $0(0)$ & $1(1.35)$ & 0.19 \\
\hline \multicolumn{4}{|l|}{ Treatment before start of anti-TNF therapy, \% } \\
\hline Oral glucocorticoids & 95 & 88 & 0.08 \\
\hline Intravenous pulse MP & 31 & 31 & 0.98 \\
\hline CSA & 75 & 78 & 0.65 \\
\hline AZA & 57 & 42 & 0.049 \\
\hline MTX & 44 & 42 & 0.77 \\
\hline Other treatments & 4 & 2 & 0.41 \\
\hline $\begin{array}{l}\text { Prednisone dosage at start of anti-TNF therapy, } \\
\text { mean } \pm \text { SD, mg/day }\end{array}$ & $54.35 \pm 15.84$ & $53.37 \pm 17.52$ & 0.37 \\
\hline Combined treatment, \%† & 76.5 & 70.3 & 0.35 \\
\hline AZA & 21.8 & 19.2 & - \\
\hline CsA & 41.1 & 55.7 & - \\
\hline MTX & 33.3 & 21.1 & - \\
\hline CYC & 1.3 & 0.0 & - \\
\hline MMF & 1.3 & 3.8 & - \\
\hline FK-506 & 1.3 & 0.0 & - \\
\hline \multicolumn{4}{|l|}{ Follow-up data } \\
\hline Duration of follow-up, mean \pm SD months & $31.52 \pm 23.51$ & $26.48 \pm 18.57$ & 0.13 \\
\hline Remission, no. (\%) & $78(76.47) \ddagger$ & $61(82.43)$ & 0.34 \\
\hline No. of relapses, mean \pm SD & $1.13 \pm 2.62$ & $1.66 \pm 8.62$ & 0.61 \\
\hline Drug discontinuation, no. (\%) & $57(55.33)$ & $21(28.37)$ & $<0.01$ \\
\hline \multicolumn{4}{|l|}{ Reason for discontinuation, no. (\%) } \\
\hline Remission & $20(19.41)$ & $6(8.1)$ & 0.58 \\
\hline Inefficacy & $18(17.47)$ & $11(14.86)$ & 0.09 \\
\hline Severe side effects/toxicity & $8(7.76)$ & $4(5.4)$ & 0.58 \\
\hline Other & $11(10.68)$ & $0(0)$ & 0.03 \\
\hline Serious side effects per 100 patient-years, mean \pm SD & $4 \pm 1.48$ & $4 \pm 2.46$ & 0.40 \\
\hline
\end{tabular}

* IFX = infliximab; $A D A$ = adalimumab; IQR = interquartile range; $B C V A$ = best-corrected visual acuity; $M P$ = methylprednisolone; $\mathrm{CSA}=$ cyclosporin $\mathrm{A} ; \mathrm{AZA}=$ azathioprine; $\mathrm{MTX}=$ methotrexate; $\mathrm{CYC}=$ cyclophosphamide; $\mathrm{MMF}=$ mycophenolate mofetil.

† Patients receiving conventional immunosuppressive drugs in combination with the anti-tumor necrosis factor (anti-TNF) agent.

‡ Data were available for 102 patients.

The degree of intraocular inflammation was evaluated according to the SUN Working Group criteria (22). Vitritis was assessed using the Nussenblatt scale (24). The best-corrected visual acuity (BCVA) was estimated using a Snellen chart. Following SUN recommendations (22), improvement in anterior uveitis activity was defined as either a 2-step decrease in the level of inflammation or a decrease to grade 0 for the level of inflammation (on a scale comprised of the grades $4,3,2,1,0.5$, and 0 ). Inactive anterior uveitis (grade 0 ) was defined as $<1$ cell per field in the anterior chamber on slit lamp examination. Worsening activity was defined as either a 2-step increase in the level of inflammation or an increase to grade 4. Similar definitions were used for improvement in and worsening of vitritis. 
Fluorescein angiography (FA) was performed to assess the presence of vasculitis. FA results were reviewed for the presence of vasculitis, papillitis, and CME. Retinal vasculitis was defined as a retinal angiographic leakage, staining, and/or occlusion on FA (4). Choroiditis and retinitis were considered active or inactive depending on the presence or absence, respectively, of activity data on ophthalmoscopic examination and/or FA.

Macular thickness was measured by high-definition optical coherence tomography (OCT), a noninvasive imaging technique that uses light waves to obtain high-resolution cross-sectional images of the retina. Scans were obtained using a $512 \times 128$ scan pattern. Macular thickening was defined as a macular thickness $>250 \mu \mathrm{m}$, whereas CME was considered to be present if macular thickness was $>300 \mu \mathrm{m}$.

The degree of immunosuppression was calculated according to the semiquantitative scale proposed by Nussenblatt et al $(25,26)$. This grading scheme provides a combined, single numeric score for the total immunosuppression load per unit of body weight per day. Each agent (prednisone, CsA, AZA, MTX, and other immunosuppressants) was graded on a scale of 0-9, except for mycophenolate mofetil, which was graded on a scale of $0-7$. For patients receiving multiple medications, the sum of the grading scores for each drug was used to calculate the total immunosuppression score on a scale of 0-15 at the baseline visit and at each subsequent visit. Topical or periocular glucocorticoid therapy was excluded from the calculation of the immunosuppression load. The biologic agent dose was not used to calculate the final immunosuppression load.

Statistical analysis. Results are expressed as the mean \pm SD for normally distributed variables and as the median (interquartile range [IQR]) for non-normally distributed variables. Continuous variables were compared by Student's 2-tailed $t$-test (for normally distributed variables) or Mann-Whitney $U$ test (for nonnormally distributed variables). The chi-square test or Fisher's exact test was used for dichotomous variables. Wilcoxon's signed rank test was used to compare continuous variables between the 2 treatment groups. BCVA, anterior chamber inflammation, vitritis, retinal vasculitis, and OCT findings were assessed at baseline (first visit before the initiation of anti-TNF treatment), 1 week, 2 weeks, 1 month, 3 months, 6 months, and 1 year and compared between time points within each group. In addition, mixed linear models were used with repeated-measures data to accommodate the effects of treatment and time and the covariation between observations for the same subject at different times. This mixed model allows greater flexibility in modeling covariance structures for repeated-measures data, and adequately accounts for the within-subject time-dependent correlations. Further, Bonferroni correction for multiple comparisons was performed in order to control for the family-wise error rate. $P$ values less than 0.05 were considered significant. Statistical analysis was performed using Statistica software (StatSoft).

\section{RESULTS}

Baseline demographic and clinical features of the patients in the IFX and ADA groups. A total of 177 patients (316 affected eyes) with uveitis refractory to conventional immunosuppressive therapy were studied (Table 1). Of these patients, 103 (58\%) were treated with IFX and 74 (42\%) were treated with ADA as a first-line biologic agent. In both groups, men slightly outnumbered women (55 men and 48 women in the IFX group versus 39 men and 35 women in the ADA group; $P=0.93$ ). The mean age was similar in both groups (mean \pm SD $40.4 \pm 10.1$ years in the IFX group and $38.7 \pm 11.3$ years in the ADA group; $P=0.29$ ). HLA-B51 was present in a similar proportion of patients in both groups (69.4\% in the IFX group versus $68.9 \%$ in the ADA group; $P=0.74)$. In most cases uveitis was bilateral $(79.61 \%$ in the IFX group versus $77.03 \%$ in the ADA group; $P=0.68$ ).

Regarding previous therapy, there were no significant differences between the 2 groups with regard to the administration of oral glucocorticoids (95\% in the IFX group versus $88 \%$ in the ADA group $[P=0.08]$; mean \pm SD maximum daily prednisone dosage $54.35 \pm 15.84 \mathrm{mg} /$ day in the IFX group versus $53.37 \pm 17.52$ $\mathrm{mg} /$ day in the ADA group; $P=0.37$ ) or IV pulse methylprednisolone (31\% in both groups; $P=0.98)$. The percentages of patients treated with CsA, MTX, and cyclophosphamide were also similar between groups (Table 1). However, a significantly higher percentage of patients in the IFX group (57\%) than in the ADA group (42\%) received AZA before the start of anti-TNF treatment $(P=0.049)$. No significant differences in the dosages of the conventional immunosuppressive drugs were observed between the IFX and ADA groups (for CsA, mean \pm SD $4.9 \pm 0.8 \mathrm{mg} / \mathrm{kg} /$ day versus $4.8 \pm 0.8 \mathrm{mg} / \mathrm{kg} /$ day $[P=0.88]$; for MTX, $15.6 \pm 4.6 \mathrm{mg} /$ week versus $16.7 \pm 3.6 \mathrm{mg} /$ week $[P=0.17]$; and for AZA, $137.2 \pm$ $32.3 \mathrm{mg} /$ day versus $127.4 \pm 25.3 \mathrm{mg} /$ day $[P=0.14]$ ). Moreover, the immunosuppression load score was similar in both groups (mean \pm SD $9.07 \pm 4.14$ in the IFX group versus $8.01 \pm 5.24$ in the ADA group; $P=0.2$ ).

The median period between the onset of uveitis and the beginning of anti-TNF therapy was also similar in both groups (36 months [IQR 12-72 months] in the IFX group versus 24 months [IQR 12-60 months] in the ADA group; $P=0.69$ ).

Visual outcome, glucocorticoid-sparing effect, and immunosuppression load score after 1 year of ADA or IFX therapy. The standard loading dose of IFX (3-5 mg/kg IV) was given at 0,2 , and 6 weeks, and patients then received a maintenance dose every $4-8$ weeks. The numbers of patients receiving each specific IFX dosing regimen were as follows: 3 $\mathrm{mg} / \mathrm{kg} \mathrm{IV}$ and maintenance dose every 4 weeks ( $\mathrm{n}=1)$, every 6 weeks $(n=2)$, and every 8 weeks $(n=5) ; 4 \mathrm{mg} / \mathrm{kg} \mathrm{IV}$ and maintenance dose every 4 weeks $(n=1)$; and $5 \mathrm{mg} / \mathrm{kg}$ IV and maintenance dose every 4 weeks $(n=15)$, every 6 weeks $(n=$ 18), every 7 weeks $(n=1)$, and every 8 weeks $(n=60)$. 
During the first year of treatment, we observed an improvement in all ocular parameters in both the IFX and ADA groups. Nevertheless, outcomes for the following parameters were significantly better in the ADA group: anterior chamber inflammation (improvement in $92.31 \%$ in the ADA group versus $78.18 \%$ in the IFX group; $P=0.06$ ), vitritis (improvement in $93.33 \%$ in the ADA group versus $78.95 \%$ in the IFX group; $P=0.04$ ), and BCVA (mean \pm SD $0.81 \pm 0.26$ in the ADA group versus $0.67 \pm 0.34$ in the IFX group; $P=0.001$ ). Patients in the ADA group had a greater improvement in macular thickness but the difference between treatment groups was not significant (mean \pm SD $250.62 \pm 36.85 \mu \mathrm{m}$ in the ADA group versus 264.89 $\pm 59.74 \mu \mathrm{m}$ in the IFX group; $P=0.15)$. A similar proportion in both groups experienced improvement in retinal vasculitis (97\% in the IFX group versus 95\% in the ADA group; $P=0.28$ ). The drug retention rate at 1 year was better in the ADA group (95.24\% versus $84.95 \%$ in the IFX group; $P=0.042$ ).

More rapid improvement of anterior chamber inflammation and vitritis was seen in the IFX group (data not shown). This finding may be explained by the fact that the patients in our series did not receive an ADA loading dose. However, better results were achieved in the patients in the ADA group after 1 year of therapy, with a significantly greater proportion of patients experiencing improvement in anterior chamber inflammation and vitritis, and a significantly higher BCVA and drug retention rate compared to the IFX group.

In order to capture within-patient correlation of repeated observations, we performed a mixed linear model using as covariates the factors shown in Table 1 that had a $P$ value of less than or equal to 0.1, as well as other plausible confounders. After adjustment for the presence of basal choroiditis and use of oral glucocorticoids or AZA before anti-TNF onset, improvement in BCVA at 12 months remained significantly better in the ADA group compared to the IFX group $(P=0.007)$. The improvement in BCVA values at different time points in the study is shown in Figure 1. When the model included the presence of vitritis, age, sex, or duration of uveitis before starting anti-TNF therapy, the results did not change. However, once the model was adjusted for these variables, there were no significant differences between the 2 treatment groups with regard to vitritis, retinitis, or OCT measurements.

One year after the initiation of anti-TNF therapy, a reduction in the immunosuppression load score was observed in both groups (from a mean \pm SD of $9.07 \pm 4.14$ in the IFX group and $8.01 \pm$ 5.24 in the ADA group at baseline $[P=0.2]$ to $5.47 \pm 3.19$ in the IFX group and $4.79 \pm 3.52$ in the ADA group at 1 year $[P=0.38]$ ). The median daily dose of prednisone was reduced in both groups, from $30 \mathrm{mg}$ (IQR 20-45) at baseline to $5 \mathrm{mg}$ (IQR 0-10) at 1 year in the IFX group and from $20 \mathrm{mg}(\mathrm{IQR} \mathrm{10-45)}$ at baseline to $5 \mathrm{mg}$ (IQR 2.5-10) at 1 year in the ADA group $(P=0.9)$.

Follow-up data and side effects of ADA and IFX. After a mean \pm SD follow-up of $31.52 \pm 23.51$ months in the IFX group and $26.48 \pm 18.57$ months in the ADA group, ocular remission was achieved in 78 (76.47\%) of 102 patients receiving IFX and in $61(82.43 \%)$ of the patients receiving ADA ( $P=0.34)$. However, the drug retention rate was significantly higher in the ADA group than in the IFX group (71.62\% versus $44.12 \% ; P<0.001)$. IFX

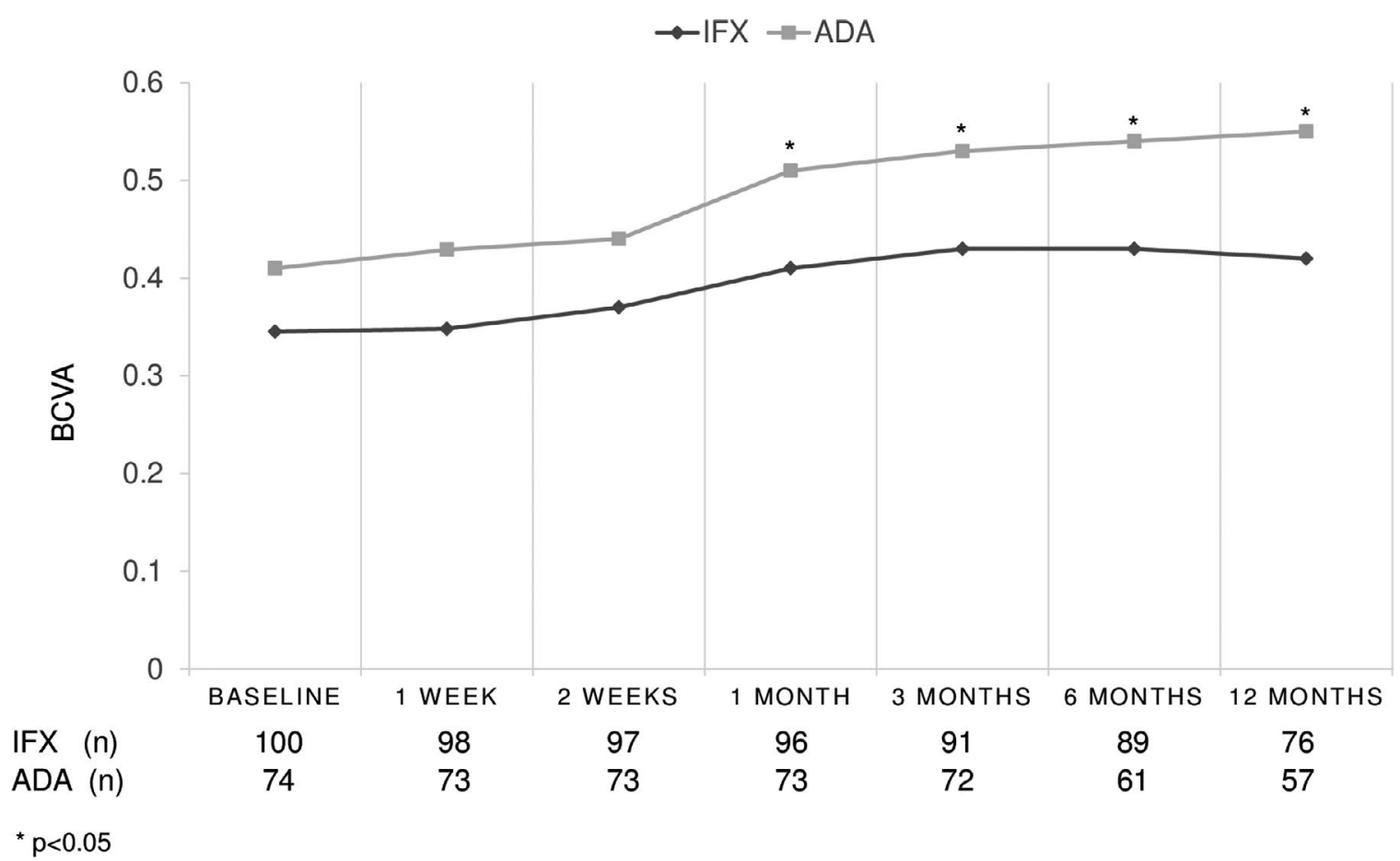

Figure 1. Adjusted best-corrected visual acuity (BCVA) at the indicated time points in the patients with Behçet's disease-related uveitis treated with infliximab (IFX) and those treated with adalimumab (ADA). Values are the mean. 
was discontinued in 57 (55.33\%) of the patients and ADA in 21 (28.37\%) of the patients $(P<0.01)$. IFX was discontinued because of remission in 20 patients. In the remaining 37 patients the reasons for IFX discontinuation were inefficacy $(n=18)$, preference for a different route of administration ( $n=9)$, toxicity/side effects $(n=8)$, colon carcinoma $(n=1)$, and desire for pregnancy $(n=1)$. ADA was discontinued due to remission in 6 patients and was discontinued in the remaining 15 patients due to inefficacy $(n=11)$ or toxicity/ side effects $(n=4)$.

Eight patients in the IFX group and 4 patients in the ADA group discontinued treatment due to severe side effects or toxicity. The 8 withdrawals from the IFX group were due to infusion reactions in 4 cases, and TB, Mycobacterium avium pneumonia, severe oral ulcers, and palmoplantar skin reaction in 1 case each. The 4 patients who discontinued ADA therapy withdrew because of Iymphoma, bacterial pneumonia, severe local reaction at the injection site, and Escherichia coli bacteremia. Data on remission, relapses, treatment discontinuation, and serious sides effects are shown for both groups in Table 1.

\section{DISCUSSION}

In this multicenter study, we report on 177 cases of refractory BD-related uveitis treated with IFX $(n=103)$ or ADA $(n=74)$ as first-line biologic therapy. After 1 year of follow up, a significantly greater improvement in BCVA, as well as a significantly higher drug retention rate, was achieved in patients treated with ADA than in those treated with IFX. However, more rapid improvement in anterior chamber inflammation and vitritis was observed in the IFX group compared to the ADA group, which could be explained in part by the fact that patients in the ADA group did not receive a loading dose of $80 \mathrm{mg}$ along with a subsequent dose of $40 \mathrm{mg}$ at 1 week as performed in the VISUAL trials, since our study was carried out before the VISUAL trials were published.

Several studies have demonstrated the presence of high levels of TNF-a potent and central ubiquitous proinflammatory cytokine-in serum and aqueous humor from patients with uveitis, including cases with BD-related uveitis (27-29). The anti-TNF agents IFX (a human-mouse chimeric IgG1 monoclonal antibody specific for TNF, administered IV) and ADA (a fully human IgG1 monoclonal antibody also specific for TNF, administered subcutaneously) have demonstrated efficacy in the treatment of BD-related uveitis refractory to conventional immunosuppressive therapy $(12,26,30-38)$.

In fact, ADA has recently been approved by the FDA and EMA for use in noninfectious intermediate, posterior uveitis and panuveitis, including cases due to BD. However, there are few studies comparing the efficacy of IFX and ADA for the induction and maintenance of remission in these patients with refractory uveitis $(11,39,40)$. Moreover, those studies generally include patients with heterogeneous diseases, with patients with BD making up a minority of the total reported cases.
The present study compared the efficacy of IFX versus ADA as a first-line biologic drug in a large series of patients with BDrelated uveitis refractory to conventional immunosuppressive drugs. Before the initiation of biologic therapy, all patients had received systemic high-dose glucocorticoids and one or more conventional synthetic immunosuppressive drugs. However, despite this treatment uveitis remained active.

Although our study showed a rapid and sustained improvement in all ocular parameters for patients in both anti-TNF drug groups, a significant difference was observed between the 2 groups with regard to BCVA improvement, which was greater in the ADA group. It is possible that the differences between the ADA group and the IFX group would have been even more evident if we had performed an intent-to-treat study instead of a per-protocol analysis because a higher percentage of patients discontinued IFX due to inefficacy.

The drug retention rate was also higher in the ADA group. This finding could be explained in part by the route of administration since ADA is given subcutaneously in a rapid and comfortable manner. Moreover, infusion reactions occur more frequently with IFX due to its chimeric nature, and the occurrence of anti-drug antibodies may also be higher with IFX.

Minor adverse effects, such as mild infusion reaction to IFX and local reactions at the site of the injection of ADA, were the most commonly observed side effects. Severe complications leading to discontinuation of the biologic therapy were observed in 8 cases in the IFX group and 4 in the ADA group. The treatment was discontinued due to inefficacy in 18 cases in the IFX group and 11 in the ADA group, comprising a low percentage of cases (17.5\% and $14.9 \%$, respectively).

We realize that this study has several limitations due to its observational nature. Therefore, further randomized, controlled trials comparing IFX and ADA head-to-head are needed.

In conclusion, we observed favorable results of both ADA and IFX therapy for BD-related refractory uveitis after 1 year of treatment, with significantly greater improvement in BCVA and higher drug retention rate in the ADA group than the IFX group.

\section{ACKNOWLEDGMENT}

The authors thank the members of the participating hospitals.

\section{AUTHOR CONTRIBUTIONS}

All authors were involved in drafting the article or revising it critically for important intellectual content, and all authors approved the final version to be published. Dr. González-Gay had full access to all of the data in the study and takes responsibility for the integrity of the data and the accuracy of the data analysis.

Study conception and design. Atienza-Mateo, Martín-Varillas, CalvoRío, González-Gay, R. Blanco.

Acquisition of data. Atienza-Mateo, Martín-Varillas, Calvo-Río, Demetrio-Pablo, Beltrán, Sánchez-Bursón, Mesquida, Adan, Hernández, Hernández-Garfella, Valls-Pascual, Martínez-Costa, Sellas-Fernández, Cordero-Coma, Díaz-Llopis, Gallego, García-Serrano, Ortego-Centeno, Herreras, Fonollosa, Garcia-Aparicio, Maíz-Alonso, A. Blanco, Torre-Salaberri, 
Fernandez-Espartero, Jovaní, Peiteado, Pato, Cruz, Férnandez-Cid, Aurrecoechea, García-Arias, Castañeda, Caracuel-Ruiz, Montilla-Morales, Atanes-Sandoval, Francisco, Insua, González-Suárez, Sanchez-Andrade, Gamero, Linares Ferrando, Romero-Bueno, García-González, Almodóvar González, Muro, Carrasco-Cubero, Olive, Prior, Vázquez, Ruiz-Moreno, Jiménez-Zorzo, Manero, Muñoz Fernandez, Fernández-Carballido, RubioRomero, Pages, Toyos-Sáenz de Miera, Martinez, Díaz-Valle, López Longo, Nolla, Álvarez, Martínez, González-López, Rodríguez-Cundin, GonzálezGay, R. Blanco.

Analysis and interpretation of data. Atienza-Mateo, Martín-Varillas, Calvo-Río, Demetrio-Pablo, Hernández, González-Gay, R. Blanco.

\section{REFERENCES}

1. Kitaichi N, Miyazaki A, Iwata D, Ohno S, Stanford MR, Chams H. Ocular features of Behçet's disease: an international collaborative study. Br J Ophthalmol 2007;91:1579-82.

2. Yurdakul S, Yazici H. Behçet's syndrome. Best Pract Res Clin Rheumatol 2008;22:793-809.

3. Taylor SR, Singh J, Menezo V, Wakefield D, McCluskey P, Lightman $S$. Behçet's disease: visual prognosis and factors influencing the development of visual loss. Am J Ophthalmol 2011;152:1059-66.

4. Tugal-Tutkun I, Onal S, Altan-Yaycioglu R, Huseyin Altunbas $\mathrm{H}$, Urgancioglu M. Uveitis in Behçet disease: an analysis of 880 patients. Am J Ophthalmol 2004;138:373-80.

5. Yang $P$, Fang $W$, Meng $Q$, Ren $Y$, Xing L, Kijlstra A. Clinical features of Chinese patients with Behçet's disease. Ophthalmology 2008;115:312-8.

6. Benezra D, Cohen E. Treatment and visual prognosis in Behçet's disease. Br J Ophthalmol 1986;70:589-92.

7. Schwartzman S. Advancements in the management of uveitis. Best Pract Res Clin Rheumatol 2016;30:304-15.

8. Levy-Clarke G, Jabs DA, Read RW, Rosenbaum JT, Vitale A, Van Gelder RN. Expert panel recommendations for the use of antitumor necrosis factor biologic agents in patients with ocular inflammatory disorders. Ophthalmology 2014;121:785-96.

9. Jaffe GJ, Dick AD, Brézin AP, Nguyen QD, Thorne JE, Kestelyn P, et al. Adalimumab in patients with active noninfectious uveitis. N Engl J Med 2016;375:932-43.

10. Nguyen QD, Merrill PT, Jaffe GJ, Dick AD, Kurup SK, Sheppard J, et al. Adalimumab for prevention of uveitic flare in patients with inactive non-infectious uveitis controlled by corticosteroids (VISUAL II): a multicentre, double-masked, randomised, placebo-controlled phase 3 trial. Lancet 2016;388:1183-92.

11. Vallet $H$, Seve P, Biard L, Fraison JB, Bielefeld P, Perard L, et al. Infliximab versus adalimumab in the treatment of refractory inflammatory uveitis: a multicenter study from the French Uveitis Network. Arthritis Rheumatol 2016;68:1522-30.

12. Calvo-Río V, Blanco R, Beltrán E, Sánchez-Bursón J, Mesquida M, Adán $\mathrm{A}$, et al. Anti-TNF-a therapy in patients with refractory uveitis due to Behçet's disease: a 1-year follow-up study of 124 patients. Rheumatology (Oxford) 2014;53:2223-31.

13. International Study Group for Behçet's Disease. Criteria for diagnosis of Behçet's disease. Lancet 1990;335:1078-80.

14. International Team for the Revision of the International Criteria for Behçet's Disease. The International Criteria for Behçet's Disease (ICBD): a collaborative study of 27 countries on the sensitivity and specificity of the new criteria. J Eur Acad Dermatol Venereol 2014;28:338-47.

15. Calvo-Río V, de la Hera D, Beltrán-Catalán E, Blanco R, Hernandez M, Martínez-Costa L, et al. Tocilizumab in uveitis refractory to other biologic drugs: a study of 3 cases and a literature review. Clin Exp Rheumatol 2014;32 Suppl 84:S54-7.

16. Calvo-Río V, Santos-Gómez M, Calvo I, González-Fernández MI, López-Montesinos B, Mesquida M, et al. Anti-interleukin-6 recep- tor tocilizumab for severe juvenile idiopathic arthritis-associated uveitis refractory to anti-tumor necrosis factor therapy: a multicenter study of twenty-five patients. Arthritis Rheumatol 2017;69: 668-75.

17. Santos-Gómez M, Calvo-Río V, Blanco R, Beltrán E, Mesquida M, Adán $A$, et al. The effect of biologic therapy different from infliximab or adalimumab in patients with refractory uveitis due to Behçet's disease: results of a multicentre open-label study. Clin Exp Rheumatol 2016;34 Suppl 102:S34-40.

18. Riancho-Zarrabeitia L, Calvo-Río V, Blanco R, Mesquida M, Adan AM, Herreras JM, et al. Anti-TNF-a therapy in refractory uveitis associated with sarcoidosis: multicenter study of 17 patients. Semin Arthritis Rheum 2015;45:361-8.

19. Calvo-Río V, de la Hera D, Blanco R, Beltrán-Catalán E, Loricera $J$, Cañal $J$, et al. Golimumab in uveitis previously treated with other anti-TNF-a drugs: a retrospective study of three cases from a single centre and literature review. Clin Exp Rheumatol 2014;32:864-8

20. Calvo-Río V, Blanco R, Santos-Gómez M, Rubio-Romero E, Cordero-Coma M, Gallego-Flores A, et al. Golimumab in refractory uveitis related to spondyloarthritis: multicenter study of 15 patients. Semin Arthritis Rheum 2016;46:95-101.

21. Atienza-Mateo B, Calvo-Río V, Beltrán E, Martínez-Costa L, Valls-Pascual E, Hernández-Garfella M, et al. Anti-interleukin 6 receptor tocilizumab in refractory uveitis associated with Behçet's disease: multicentre retrospective study. Rheumatology (Oxford) 2018;57:856-64.

22. The Standardization of Uveitis Nomenclature Working Group. Standardization of uveitis nomenclature for reporting clinical data: results of the First International Workshop. Am J Ophthalmol 2005;140: 509-16.

23. Bloch-Michel E, Nussenblatt RB. International Uveitis Study Group recommendations for the evaluation of intraocular inflammatory disease. Am J Ophthalmol 1987;103:234-5.

24. Nussenblatt RB, Palestine AG, Chan CC, Roberge F. Standardization of vitreal inflammatory activity in intermediate and posterior uveitis. Ophthalmology 1985;92:467-71.

25. Nussenblatt RB, Peterson JS, Foster CS, Rao NA, See RF, Letko $\mathrm{E}$, et al. Initial evaluation of subcutaneous daclizumab treatments for noninfectious uveitis: a multicenter noncomparative interventional case series. Ophthalmology 2005;112:764-70.

26. Díaz-Llopis M, Salom D, Garcia-de-Vicuña C, Cordero-Coma M, Ortega G, Ortego N, et al. Treatment of refractory uveitis with adalimumab: a prospective multicenter study of 131 patients. Ophthalmology 2012;119:1575-81.

27. Santos Lacomba M, Marcos Martín C, Gallardo Galera JM, Gómez Vidal MA, Collantes Estévez E, Ramírez Chamond R, et al. Aqueous humor and serum tumor necrosis factor-a in clinical uveitis. Ophthalmic Res 2001;33:251-5.

28. Pérez-Guijo V, Santos-Lacomba $M$, Sánchez-Hernández $M$, del Carmen Castro-Villegas M, Gallardo-Galera JM, CollantesEstévez E. Tumour necrosis factor-a levels in aqueous humour and serum from patients with uveitis: the involvement of HLA-B27. Curr Med Res Opin 2004;20:155-7.

29. Nakamura S, Sugita M, Tanaka T, Ohno S. Enhanced production of in vitro tumor necrosis factor-a from monocytes in Behçet's disease. Nippon Ganka Gakkai Zasshi 1992;96:1282-5.

30. Okada AA, Goto H, Ohno S, Mochizuki M, for the Ocular Behçet's Disease Research Group of Japan. Multicenter study of infliximab for refractory uveoretinitis in Behçet disease. Arch Ophthalmol 2012;130:592-8.

31. Sugita S, Yamada Y, Mochizuki M. Relationship between serum infliximab levels and acute uveitis attacks in patients with Behçet disease. Br J Ophthalmol 2011;95:549-52. 
32. Keino H, Okada AA, Watanabe T, Taki W. Decreased ocular inflammatory attacks and background retinal and disc vascular leakage in patients with Behçet's disease on infliximab therapy. Br J Ophthalmol 2011;95:1245-50.

33. Tugal-Tutkun I, Mudun A, Urgancioglu M, Kamali S, Kasapoglu E, Inanc $\mathrm{M}$, et al. Efficacy of infliximab in the treatment of uveitis that is resistant to treatment with the combination of azathioprine, cyclosporine, and corticosteroids in Behçet's disease: an open-label trial. Arthritis Rheum 2005;52:2478-84.

34. Niccoli L, Nannini C, Benucci M, Chindamo D, Cassarà E, Salvarani C, et al. Long-term efficacy of infliximab in refractory posterior uveitis of Behçet's disease: a 24-month follow-up study. Rheumatology (Oxford) 2007;46:1161-4.

35. Bawazeer A, Raffa LH, Nizamuddin SH. Clinical experience with adalimumab in the treatment of ocular Behçet disease. Ocul Immunol Inflamm 2010;18:226-32.

36. Takase K, Ohno S, Ideguchi H, Uchio E, Takeno M, Ishigatsubo Y. Successful switching to adalimumab in an infliximab-allergic pa- tient with severe Behçet disease-related uveitis. Rheumatol Int 2011;31:243-5.

37. Perra D, Alba MA, Callejas JL, Mesquida M, Ríos-Fernández R, Adán A, et al. Adalimumab for the treatment of Behçet's disease: experience in 19 patients. Rheumatology (Oxford) 2012;51: 1825-31.

38. Calvo Catalá J, Campos Fernández C, Rueda Cid A, González-Cruz Cervellera MI, Baixauli Rubio A, Pastor Cubillo MD. Efficacy of adalimumab in Behçet's disease: description of 6 cases. Reumatol Clin 2011;7:258-61.

39. Zannin ME, Birolo C, Gerloni VM, Miserocchi E, Pontikaki I, Paroli MP, et al. Safety and efficacy of infliximab and adalimumab for refractory uveitis in juvenile idiopathic arthritis: 1-year followup data from the Italian Registry. J Rheumatol 2013;40:74-9.

40. Simonini G, Taddio A, Cattalini M, Caputo R, De Libero C, Naviglio S, et al. Prevention of flare recurrences in childhood-refractory chronic uveitis: an open-label comparative study of adalimumab versus infliximab. Arthritis Care Res (Hoboken) 2011;63:612-8.

DOI 10.1002/art.41061

\title{
Clinical Image: Palate erosions in reactive arthritis
}

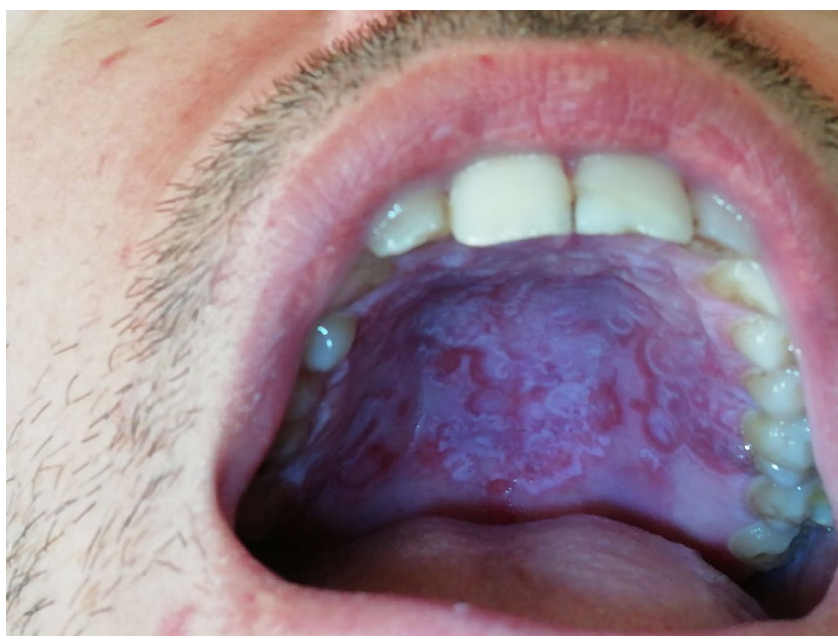

The patient, a 37-year-old man who had experienced HLA-B27-associated reactive arthritis (ReA) in 2011, presented to the rheumatology department with a new episode of oligoarthritis, dactylitis of 1 toe, and enthesitis of the Achilles tendon. Additionally, symptoms of dysuria had occurred and were resolved 6 weeks prior, and circinate balanitis and severe yet painless hard palate erosions had been present for 4 weeks. There were no symptoms of conjunctivitis. A urinary white blood cell count was normal, and polymerase chain reaction for Chlamydia trachomatis was negative. A serum sample was obtained to test for human immunodeficiency virus, hepatitis $B$ virus, hepatitis $C$ virus, and Treponema pallidum; all had negative findings. A new exacerbation of HLA-B27-associated ReA was diagnosed. High-dose glucocorticoid treatment was unsuccessful, but local glucocorticoid injected into the elbow and systemic treatment with etoricoxib (120 $\mathrm{mg}$ ) relieved symptoms. Sulfasalazine (2 gm/daily) was prescribed. The mucocutaneous lesions spontaneously healed. Mucocutaneous lesions are common in ReA, typically presenting as painless, superficial, erythematous, white-bordered erosions or ulcers on the lips, tongue (comparable with lingua geographica in psoriasis), and genitals (known as circinate balanitis). This patient, however, presented with painless erosions on the hard palate, a rare manifestation in ReA.

\author{
Stijn Michiels, MD iD \\ Imelda Hospital \\ Bonheiden, Belgium \\ and University Hospitals Leuven \\ Leuven, Belgium \\ Stefan Kerre, MD \\ Imelda Hospital \\ Bonheiden, Belgium
}

